\title{
A tale of three tribes: UK MPs, Twitter and the EU Referendum campaign ${ }^{1}$
}

\author{
Liam McLoughlin $^{\mathrm{a}}$, Stephen Ward ${ }^{\mathrm{a}, *}$, Rachel Gibson $^{\mathrm{b}}$ and Rosalynd Southern ${ }^{\mathrm{c}}$ \\ ${ }^{a}$ School of Arts and Media, University of Salford, Salford, UK \\ ${ }^{\mathrm{b}}$ Cathie Marsh Institute for Social Research, University of Manchester, Manchester, UK \\ ${ }^{c}$ Department of Communication and Media, University of Liverpool, Liverpool, UK
}

\begin{abstract}
This paper examines the structure of Twitter communication networks between MPs during the 2016 EU Referendum campaign. In particular, the research examines the impact of Twitter in two dimensions: (1) how far social media might facilitate inter-party linkages thus eroding traditional partisan relations between MPs? This was given added potential by the supposedly cross-party nature of the Referendum campaign and, therefore, we specifically examined the collective communicative networks that formed around Leave and Remain amongst MPs; (2) Given the potential of social media to provide a platform for individual politicians to personalize campaigns, we asked how far social media might disrupt traditional formal intra-party hierarchies? Did, for example, backbench or relatively unknown figures come to the fore in the EU debate? Our results indicate that whilst there existed a high degree of partisanship, interestingly, Remainer MPs tended to adhere to party networks resulting in a divided remain network. By contrast, the Leave network was more unified but also more porous. Within the networks themselves, the centrality of individual MPs did not always reflect their formal status.
\end{abstract}

Keywords: EU Referenda, MP networks, Twitter, inter-party, intra-party

Key points for practitioners:

- Methodologically, social media network analysis provides us with window on politicians' interpersonal networks that would previously have been difficult to access.

- Our findings have implications for campaigners in referenda. The results here found that partisanship trumped remain in terms of the overall remain campaign. This produced a divided remain network with potentially damaging results for clarity of the campaign.

- Social media technologies are disrupting traditional party and parliamentary hierarchies by allowing greater focus on personalities and individuals beyond just traditional party office holders.

\section{Introduction}

In the UK, as in many democracies, there has been a rapid rise of MPs using Twitter over the past decade. From being a relative novelty in 2010 , over one parliamentary cycle, the technology had been normalized by 2016 with 576 MPs having Twitter accounts by the time of the EU referendum (McLoughlin, 2016). Research in this area has tended to focus on the use of technology for representative and

\footnotetext{
${ }^{1}$ An early version of this paper entitled: 'MPs, Twitter and the EU Referendum Campaign' by the same authors was presented at the Elections, Parties and Opinion Polls (EPOP) Conference, University of Kent, 8-10 $0^{\text {th }}$ September 2016.

${ }^{*}$ Corresponding author: Stephen Ward, School of Arts and Media, Crescent House, University of Salford, Salford, M5 4WT, UK. Tel.: +44 161295 2803; E-mail s.j.ward@salford.ac.uk.
} 
2 L. McLoughlin et al. / A tale of three tribes: UK MPs, Twitter and the EU Referendum campaign

participatory purposes, political marketing and campaigning, or more broadly on changes in style of representative democracy (Jackson \& Lilleker, 2011; Margolis \& Moreno-Riano, 2013; Kruikmeier, 2014). However, far less attention has been devoted to the arguably less high-profile world either issue-based discussion or communication networks between political representatives. This is despite some evidence of the use of platforms such as Twitter for discussions with other political representatives (Sæbø, 2011). Thus, this research starts to approach communication from this perspective. This is through an analysis of the communicative networks being fostered by social media between MPs and what this means for campaigns and behaviour within and between parliamentary parties. In particular, we are interested in examining how far social media are, or are not, challenging both inter and intra-party relationships. Whilst there has been much popular comment on the disruptive nature of technologies (Margetts et al., 2015), much of the existing empirical research suggests a more conservative approach in the politi$\mathrm{cal} /$ parliamentary sphere. Some studies suggest far from challenging political representatives' behaviour or power structures and elites within parties - online campaigning has hardened divides both between parties (Gibson \& Ward, 2009, 2012; Margolis \& Resnick, 2001). However, more recent work has suggested that social media may be challenging traditional power structures in terms of who dominates campaigns (Jackson \& Lilleker, 2010; Schweitzer, 2011; Gibson, 2013; Southern, 2015; Southern \& Lee, 2019) with more decentralised and open formats.

Our research examines these broad questions within the more specific context of MPs' online networks during the UK EU referendum debate. The referendum arguably offered rare opportunities for crossparty linkages, with MPs able to explain publicly their own individual (as opposed to a party), position on Britain's relationship with the EU stance as well as a chance for a sustained national discussion/debate focused around a single issue. This makes it an ideal case-study with which to examine the erosion of barriers to inter-party politics in public political discourse online.

\section{Literature review}

The rapid growth of platforms such as Twitter across many democracies has prompted considerable interest about the meaning of social media networks might and whether they provide any other than a superficial representation of relationships between individuals, groups and organisations (SandovalAlmazan and Valle-De Cruz, 2018). In the political sphere, debates have concentrated on to how far social media might enhance, erode, or disrupt democratic relationships and institutions (Effing et al., 2011). The research here focuses some of these general concerns into the more specific context of parliamentary party networking around a contentious issue (Brexit) to assess whether social media might disrupt tradition partisan networks both between and within, political parties.

\subsection{Inter-party politics: Is the Internet eroding party barriers?}

The internet and social media are often seen as reducing the costs of networking and linkages especially given their relative ease of use and lack of editorial controls (Lassen \& Brown, 2010). In a parliamentary context, one expectation when social media first emerged was that technologies would allow different types of relationships to develop such as allowing ordinary backbenchers to challenge government ministers more effectively or reflecting institutional relationships across parties. For example, connecting MPs on the same parliamentary committees more effectively and allowing them to call for shared policies or measures across party lines (Lusoli \& Ward, 2005). Theoretically, at least, social media could support an erosion of traditional partisan relationships in favour of more open and 
mixed networks between representatives, eroding partisanship rather than entrenching it. Whilst this argument might have technological potential, it underestimates the resilience of traditional partisan political networks and the strength of parliamentary party discipline in many parliaments. For instance, one Norwegian study found there was little identifiable desire to move away from party attachments (Enli \& Skogerb $\varnothing$, 2013). Indeed, what this theory perhaps underplays is that technology is often reflective of the institutional and political environment within which it operates (Leston-Bandeira, 2007). Furthermore, even if technology reduces the costs of networking the effect would not be evenly distributed. Hence, the internet and social media are arguably most effective at helping sustain like-minded networks. This has been referred to as the homophily or 'birds of feather flock together' argument (Granovetter, 1983) whereby individuals gravitate towards networks with people of similar interests (McPherson et al., 2001; Larsson \& Ihlen, 2015; Himelboim et al., 2013). This has been then linked to a supposed "echo-chamber" effect which potentially strengthens pre-existing opinions, prejudices and polarises debates through selective exposure (Sunstein, 2006; Bright 2016). There are challenges to these assertions however. Several studies found little evidence to support either homophily or echo chambers in social media networks. Barbera (2015) and Gil de Zúñiga and Valenzuela (2011) found many cases of Twitter users coming into contact with more diverse opinions that ones that simply supported their existing views and DuBois and Blank (2018) found that varied online media diets increased the chance of one being in a network whereby one would come across views one might disagree with via incidental or accidental exposure (Valeriani \& Vaccari, 2016; Fletcher \& Nielson, 2018).

The limited empirical evidence on parliamentary social media networks, however, tends to bear the homophily assertion out. Although Miller (2015) found some evidence for cross party connections forming in the UK, research indicate that social media networks are highly reflective of their political systems and party environments (Gibson \& Ward, 2009, 2012; Thamm \& Bleier, 2013; Hsu \& Park, 2012; Rauchfleisch \& Metag 2016). Hence, in adversarial party systems like the UK, with a relatively limited numbers of parliamentary parties, social media networks between MPs seemingly mirror offline polarization (NESTA, 2015). In short, MPs unsurprisingly, tend to network most closely with their own party. The picture is marginally different in federal multi-party systems where there is more of a culture of cooperation and coalition more and, therefore, more social media cross-over between MPs (Nevertheless, though, there remains limited study of parliamentary networking via social media platforms especially around specific issues or debates.

\subsection{Intra-party politics: Is social media eroding hierarchies?}

Even if social media doesn't break down party boundaries, one could suggest that social media could facilitate challenges to intra-party politics (Gibson \& Ward, 2009, 2012; Jacobs \& Spierings, 2016). It has been argued that new technologies could erode traditional party and parliamentary hierarchies by encouraging decentralist and individualistic tendencies (Karvonen, 2010; van Aelst et al., 2012). One argument is that social media and the internet generally allow individual MPs a more open and level communication playing field than they would get through, say, the traditional media. In most western democracies, studies indicate that newspaper and broadcast media have increasingly narrowed their focused on a handful of politicians and leading ministers with backbench parliamentarians receiving less and less coverage (Negrine, 1999; Negrine \& Lilliker, 2003; Tresch 2009; Deacon \& Wring, 2011). However, the internet offers ordinary MPs a low-cost mechanism of communication not controlled by editors or other media gatekeepers. Whilst party elites still have the advantage of traditional media coverage, the internet world could at least allow, if not a levelling, a widening of the this sphere, permitting 
4 L. McLoughlin et al. / A tale of three tribes: UK MPs, Twitter and the EU Referendum campaign

MPs to become known for a particular cause or centre themselves within a network without needing the help of traditional journalists in order to do so. A recent study of the Catalan Parliament, for example, detected the growth of online influencers and brokers who drew their strength not from formal institutional positions but from their centrality to online networks (Del Valle \& Borge, 2017). One early example of this in the UK would be the way that Tom Watson, now Labour's Deputy Leader but that the time a relative unknown, harnessed social media to make a name for himself around regulation of the press and subsequently as one of the key proponents of the Leveson Reforms (Francoli \& Ward, 2008). Social media could allow other relatively junior MPs a platform by which to stand out in a way that might have been difficult without them. Several UK backbench MPs have attained prominence online and used social media to campaign effectively. For example, Stella Creasy in her campaign against legal loan sharks (Binns, 2018) and, more recently, David Lammy in his campaigns on Grenfell tragedy and the Windrush deportation scandal (Lo Dico, 2018). In addition to offering this greater general communication presence, social media also allows MPs a greater opportunity to personalise party messages, make their own opinions heard and explain their own policy/issue stance which may diverge from the party line. Hence, social media could accelerate tendencies toward personalisation and individualization of politics detected since the 1980s (Kruikemeier, 2014).

Interrelated to presence and personalisation is the notion that social media platforms allow MPs to express dissent more easily and to challenge party leaderships (Gibson \& Ward, 2018). Given the ease, speed, and low costs of communication now available, it has become increasingly difficult for parties to control communication flows despite the apparent growth in leadership resources in many parties since the 1980s. Certainly, there are indications that social media is increasingly disrupting traditional UK party politics and making it less predictable. Jeremy Corbyn's rapid rise to Labour leadership from an outsider position has been attributed in part to support inflated by Twitter/social media networks (Prince, 2016; Gilbert, 2015). Whether the rise of some outsider or populist politicians represents decentralist or democratization of parties is more debatable. One could of course argue that new media environments are simply accelerating the trend towards an increase in new forms of elite politicians through the promotion of personality traits or celebrity-style charisma (Van Zoonen, 2005). However, it is a question that is unlikely to disappear particularly as social media has seemed to contribute to the stratospheric rise of previously obscure politicians, including the recent examples of Beto O'Rourke and Alexandria OcasioCortez in the US (Gallucci, 2018).

Our case study here can also offer insights on two further literatures. Firstly, our data are a proxy in some sense for the unity of the two campaign camps (Leave and Remain). Assessing the communication linkages between these camps, which were often made up of members of opposing parties will shed some light into how unified networks were, or at least wanted to appear, in their social media campaigning. Literature on this topic suggests that campaigns can often suffer if there is apparently disunity or discord (Norris et al., 1999; Cantor \& Hernson, 1997; Simon, 2002). The Twitter campaign data employed here can offer an important insight into this aspect of the campaign and could have broader implications for campaign strategic communications more broadly. This also offers an opportunity to further learn about whether partisanship endures in free votes. This is usually something studies within the context of parliamentary votes but this case offers an important insight into this question outside of the voting chamber. Work in this area suggests that partisanship is highly cohesive even when votes are not whipped. Cowley and Stuart (1997: 1) assessed free votes between 1979 and 1996 and found a high level of voting along party lines even when the 'whips were off'. Even on issues of conscience, which are often unwhipped as such matters are seen as being above party, Cowley (1998) found high degrees of partisanship. The EU referendum was deemed a free vote for both main parties being considered as an 
issue that cut across parties also. Assessing partisanship in this campaign will, therefore, offer important new insights into the entrenchment of partisanship outside of the confines of the voting chamber, which may still remind MPs of their party allegiances.

\subsection{The EU Referendum as a case study for exploring the erosion of inter-party barriers and intra-party hierarchies}

The 2016 Referendum debate offered a useful opportunity to look afresh at some of the potentially disruptive challenges of new technologies. As discussed, much of the empirical research thus far suggested a relatively conservative approach to technologies by MPs and parties and limited impact in highly traditional political sphere. The EU referendum presented a good test case for a number of reasons: Firstly, this was a focused debate that crossed party boundaries and divided parties (the Conservatives especially, although some prominent Labour figures were also pro-Leave, against the prevailing Party line). ${ }^{2}$ The campaign was in theory cross-party, offering a chance for new networks to be created not simply based on party linkages/ideology. Moreover, the referendum debate, given that it divided parties, also risked heightening internal divides. Furthermore, whilst campaigns were led by well-known leading politicians, the social media world potentially allowed other voices to be heard and for MPs more generally to clearly state their own individual personal positions.

\section{Research questions and methodology}

With the above discussion in mind, therefore, we focussed on the following questions:

(1) From the inter-party perspective - was social media helping foster cross party networking during the campaign? More specifically, was partisanship or policy (i.e. Leave/Remain) stronger in the formation of elite communication networks on social media during the EU referendum campaign?

(2) In terms of the intra-party arena - was social media facilitating the erosion of traditional party and institutional hierarchies by allowing backbenchers to gain greater prominence and centrality within intra-MP campaign discourse?

\subsection{Operationalising the research questions and collecting the data}

Traditionally, researching the ways political representatives communicate between themselves is a difficult challenge. Permission to access the behind the scenes communication from in person, letter, or email would be complicated, and the ethical considerations would be significant. However, with MPs uptake of social media, a glimpse of their interpersonal communication now takes place online in a way that is accessible and open to examination. Assessing these communications can provide insights into the networks at play during the campaign, and the prominence of MPs within these camps. To do this, we took interactions between MPs on Twitter. This provides us with a novel method for understanding the network of communication that occurs between elites and the patterns we see within them. This is an aspect of campaigning that is hitherto under researched, largely due to the difficulty of acquiring reliable information on communication between elites. Twitter was used as a basis for study due the relative

${ }^{2}$ Kate Hoey, Gisela Stuart, Frank Field, Kelvin Hopkins and Graham Stringer being the most prominent Labour Leavers. 
$\underline{6}$ L. McLoughlin et al. / A tale of three tribes: UK MPs, Twitter and the EU Referendum campaign

Table 1

Total number of Tweets by party

\begin{tabular}{lcccrr}
\hline \multicolumn{1}{c}{ Party } & $\begin{array}{c}\text { MPs in } \\
\text { sample }\end{array}$ & $\begin{array}{r}\text { MPs in filtered } \\
\text { data }\end{array}$ & $\begin{array}{c}\text { Number of Tweets } \\
\text { by MPs }\end{array}$ & $\begin{array}{r}\text { Tweets EU } \\
\text { related }\end{array}$ & $\begin{array}{r}\text { Tweets EU } \\
\text { related }(\%)\end{array}$ \\
\hline Conservative & 275 & 152 & 2,828 & 906 & 32.0 \\
Labour & 210 & 148 & 4,353 & 862 & 19.8 \\
Green & 1 & 1 & 25 & 8 & 32.0 \\
DUP & 7 & 0 & 39 & 0 & 0.0 \\
Liberal democrat & 8 & 4 & 129 & 18 & 14.0 \\
Plaid Cymru & 3 & 2 & 42 & 6 & 14.3 \\
SNP & 54 & 32 & 681 & 92 & 13.5 \\
SDLP & 3 & 2 & 18 & 4 & 22.2 \\
Sinn Féin & 4 & 0 & 5 & 0 & 0.0 \\
UKIP & 1 & 1 & 26 & 13 & 50.0 \\
UUP & 2 & 0 & 3 & 0 & 0.0 \\
Total & 568 & 342 & 8,149 & 1,909 & 23.4 \\
\hline
\end{tabular}

openness of data collection due to its streaming $\mathrm{API}^{3}$ and as it has become the main type of social media used by MPs to communicate publicly (Southern \& Lee, 2018).

For this research, we collected every message sent between MPs on Twitter during the official EU referendum campaign (15 $5^{\text {th }}$ April to $23^{\text {rd }}$ June 2016). To do this, we identified all MPs with a Twitter account and added their Twitter handles to a database. To ensure that no fake profiles entered the database, each MPs handle was confirmed through Twitter's verified status service and via their biography on Parliament.uk. Through this process, we found that 576 out of 650 MPs had a Twitter account.

The dataset on MPs handles was applied to a data acquisition software that integrates with Twitter's streaming API called NodeXL. This collected all the Tweets, Retweets, Replies and Mentions (referred to as actions in this paper (Smith et al., 2010)) between all MPs over the course of the data collection period. During the data collection period eight MPs made no communication on Twitter and are therefore not included in the dataset. This produced a dataset of 8,149 actions, which we believe represents the entirety of all communication between MPs on Twitter during the referendum campaign. From the collected data of 8,149 actions between MPs, the majority came from mentions $(6,681)$, while 1,244 came from tweets, and replies only made up 224 of the total. Furthermore, the dataset, which comprises follower relationships between MPs, includes 51,348 separate connections.

It must be noted that during the data collection period, there was several events of political importance that were exogenous to the research focus. These included, a number of other local elections and most notably the murder of Jo Cox MP (a Labour remain supporting MP) by a right wing extremist that led to the suspension of the campaign for a few days. These events shaped a significant amount of communication between MPs on social media. These were filtered out of our data post-hoc leaving only data that directly referenced the EU or the referendum. ${ }^{4}$ The results of this can be seen in Table 1.

Network analysis software Gephi (Bastian et al., 2009) was then employed to analyse the data. This was used as a visual and numerical method of understanding the groupings that formed within this elite interpersonal communication network. Furthermore, we were also able to use Gephi to find which MPs had the most importance in the networks and if the online discussions were led by particular MPs.

${ }^{3}$ API stands for 'Application Programming Interface' - an API is a way for programs and other software to retrieve and modify data from an external source, bypassing website interfaces. In this instance Twitter allows access to two separate APIs: the streaming API, and search API. Each allow access to different data and usage of each is selected dependent on requirements. ${ }^{4}$ Only retained tweets that directly contained words or hashtags relevant to the EU, the referendum campaign, or either 


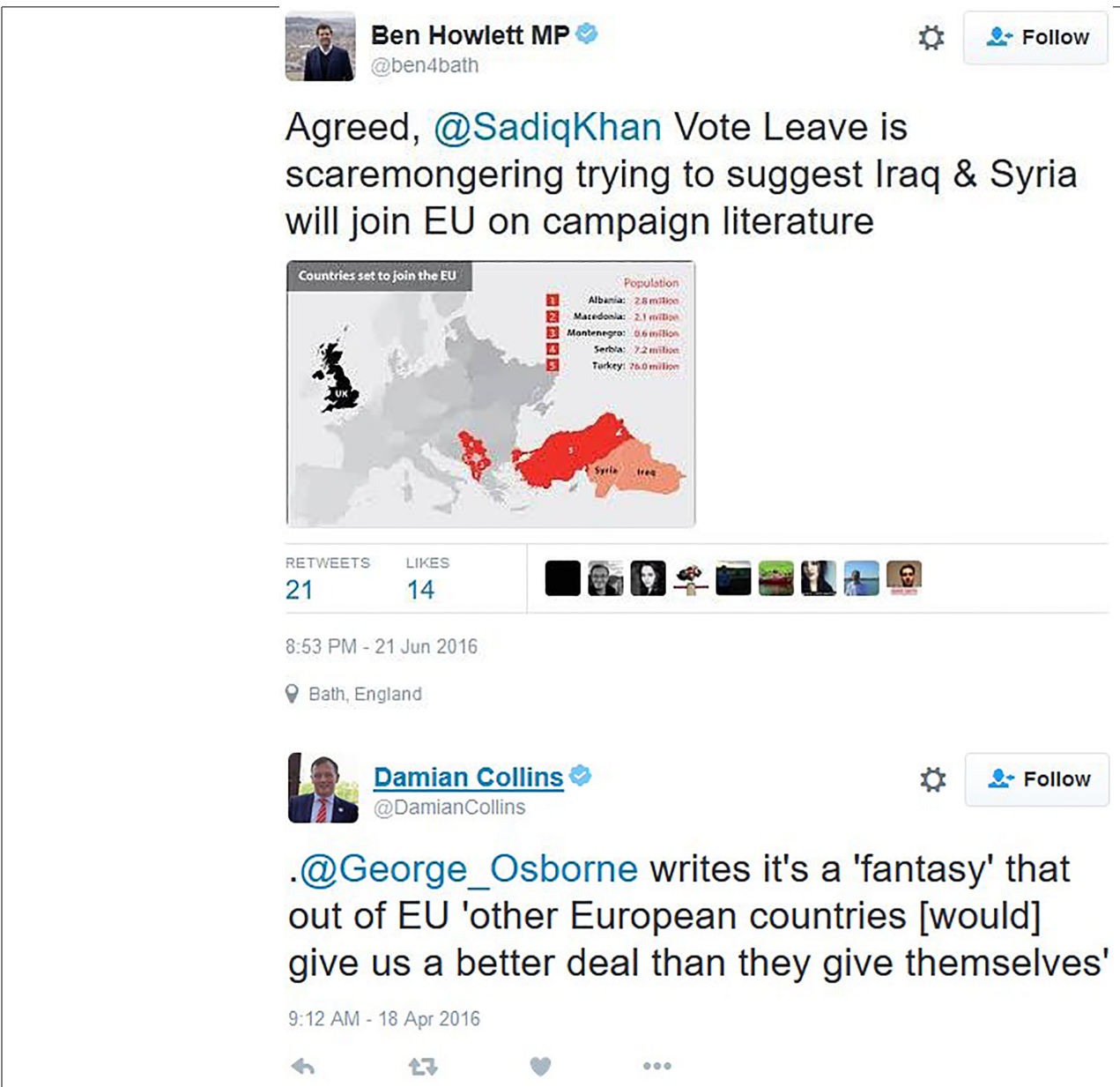

Fig. 1. Examples of actions between MPs on Twitter. These two images show the types of tweets collected within the dataset. The first image on the right shows Ben Howlett MP mentioning Sadiq Khan MP. The second tweet on the right shows Damian Collins MP directly tweeting to George Osborne MP.

\subsection{Ethics}

Whenever using data taken from social media, it is important to ensure rigorous ethical standards. Therefore, we implemented the ethics frameworks from a number of sources (Markham \& Buchanan, 2012; Salmons \& Woodfield, 2013; Beninger, 2014). This includes insuring that the methodology only took place from only publicly accessible data. Data from private Twitter accounts were not collected. Furthermore, it can be assumed that MPs are public figures and use social media to send messages to a public audience, and are not concerned about the messages they post being in the public domain.

Data was only collected on verified MPs; therefore, no members of the public are part of the data set. In accordance with Twitter's developer agreement and policy agreement (Twitter, 2016), no tweets deleted by MPs are published as part of this paper.

remain or leave campaign hashtags. So tweets containing the words or hashtags EU, referendum, European Union, euro, \#EU, \#Referendum, \#voteleave, \#UKinEU, \#brexit, \#stayin, \#LabourInForBritian, \#strongerout. 
8 L. McLoughlin et al. / A tale of three tribes: UK MPs, Twitter and the EU Referendum campaign

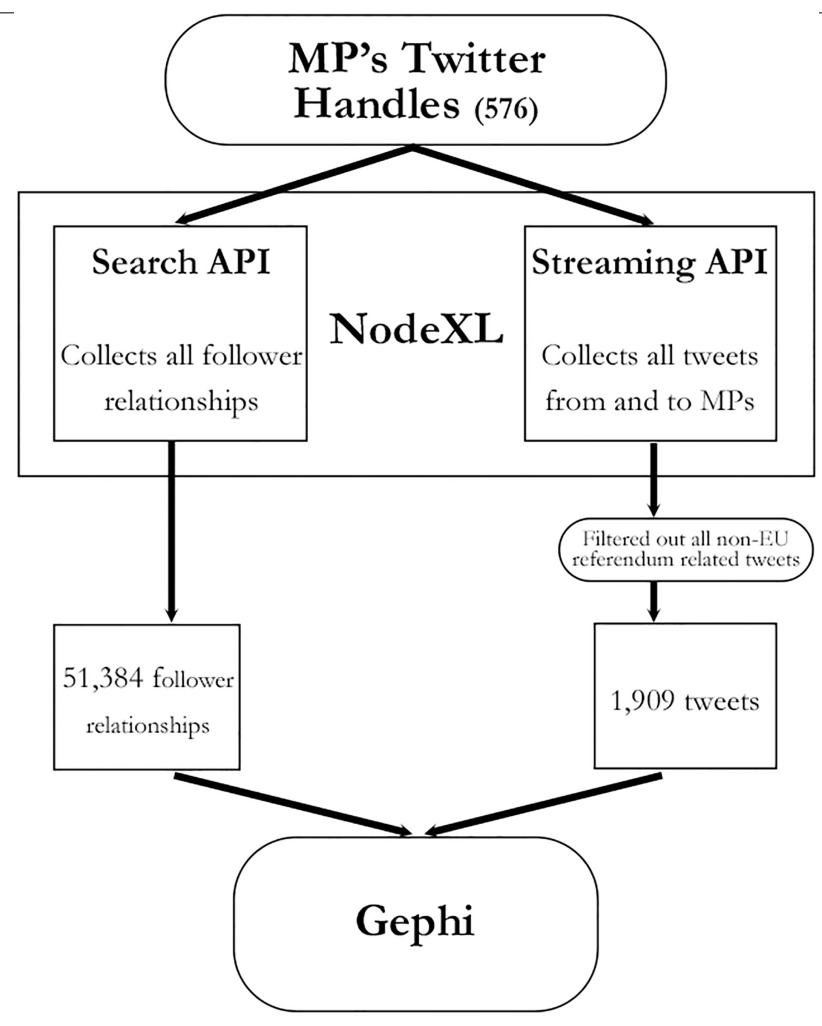

Fig. 2. Methodology schema.

\section{Findings}

\subsection{Understanding network analysis}

The research deployed social network analysis (SNA) to understand communities by visualising them as a network. SNA allows researchers to pinpoint social structures, groups, or even key individuals within the online sphere (Bandyopadhyay et al., 2011). For this research, a series of network graphs was created to visualise the data collected in this research. These network graphs are made up of nodes, which symbolise each user in the network, and edges, which show the relationship between the nodes. In these graphs, where there are more connections between two nodes, this will be visualised by a relative closeness between them on a graph. We have also displayed the importance of each node through size using a measure called centrality. Nodes with a higher level of centrality have a more central role within the network (Gruzd et al., 2018, p. 728). To demonstrate centrality, we have adjusted the size of each mode relative to their importance within the network. Another measure used as part of this research is modularity, this is a statistical measure that determines whether densely connected participants in the network represent distinct communities or not. This uses the algorithm by Blondel et al. (2008) that is available through the Gephi software package.

\subsection{Follower relationships between MPs}

Follower relationships on Twitter are asymmetrical connections between two people that allows the 


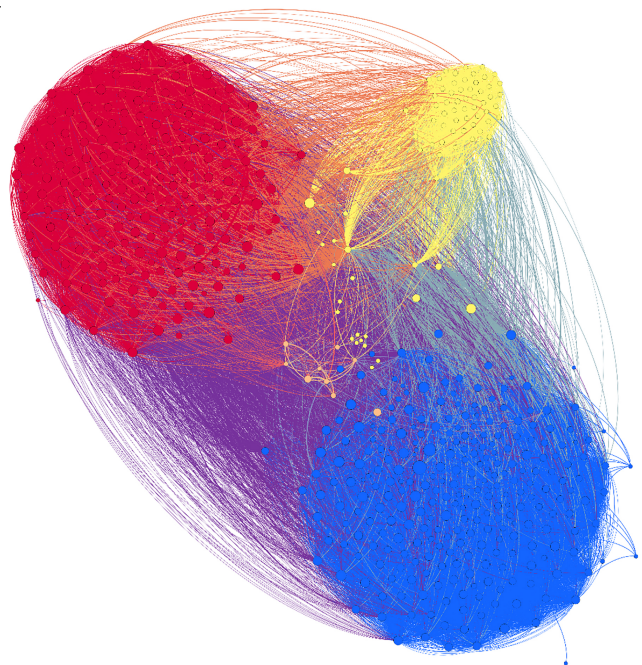

Graph 1. Follower relationships of MPs; nodes coloured by party. Created using Force Atlas 2 Layout. Each MP (displayed as nodes) has been identified by the party they represent: Blue, Conservative - Red, Labour - Yellow, SNP - Liberal Democrats, Orange - Grey; Other. The size of the Nodes and Labels are dependent on their importance within the network (Eigenvector).

follower to receive updates of the followee within their social network streams. Takemura et al. (2015) sought to understand the significance between a follower and found that there is not one singular reason for why one user would choose to follow another. Instead, there are a number of interconnected factors that induce follower relationships that include information gathering, as a method of enacting personal communication, showing support for the followee, or simply as a method to see what the user is up to. Although the reason for an MP to follow another MP is undetermined, followers are a useful method of being able to see how the networks of particular set of people are grouped. Furthermore, understanding the network based from follower relationships is a useful method for measuring longstanding relationships on Twitter between MPs. As the networks based upon following is more stable than tweets, retweets or mentions, which are more dependent on political climates. Consequently, we are able to use follower networks to create a baseline perspective of MPs' networked groups.

An initial examination of the data looking at the follower relationships suggests that MPs on Twitter are extremely interconnected. We located 51,348 follower connections between MPs meaning that MPs follow on average 90.4 other MPs. However, this differed by party. Conservative and Labour MPs followed the most, following 93.6 and 102.1 MPs. Meanwhile MPs from other parties followed other MPs significantly less, with SNP MPs and all other party MPs following 60.3 and 31.8 respectively. This suggests that MPs will mostly limit who they follow to MPs of their own party, as MPs from the larger parties, with the most MPs, would have more colleagues to follow.

Indeed, SNA analysis goes on to confirm the highly partisan nature of MPs follower relationships in the UK. From the total of 51,348 follower connections, only 10,896 (21.2\%), of the relationships cross party lines. To investigate this relationship, we created Graph 1 which visualises the follower network amongst MPs through the use of the Force Atlas 2 Layout. The Force Atlas 2 algorithm works by having 'nodes repulse each other like charged particles, while edges attract their nodes, like springs', this results in a graph that shows the closeness of a network by turning structural proximities into visual ones (Jacomy et al., 2014 PAGE). As a result, it displays follower networks on Twitter, with the closer nodes (or MPs) showing a stronger networked grouping. Graph 1 shows the overall follower network with MPs with each node coded by the MPs respective party. This graph highlights how much closer 
Graph 2. MPs network of communication based from actions during the referendum campaign coloured by party. Created using OpenOrd Layout. Each MP (displayed as nodes) has been identified by the party they represent. Blue, Conservative; Red, Labour; Yellow, SNP; Liberal Democrats, Orange; Grey; Other. The size of the Nodes and Labels are dependent on their importance within the network (Eigenvector).

MPs from the same party are than with other MPs. This again signifies the highly partisan nature of MPs online networks. Although the edges display some cross-party relationships, these are not as significant as the relationships between party colleagues. This would suggests that MPs do not tend to follow a wide variety of MPs, but are more selective about which MPs they follow on Twitter, with the majority of these connections identifiably partisan as they strongly correlate with party affiliation. 
L. McLoughlin et al. / A tale of three tribes: UK MPs, Twitter and the EU Referendum campaign

Table 2

\begin{tabular}{|c|c|c|c|c|c|c|c|c|}
\hline \multicolumn{9}{|c|}{$\begin{array}{c}\text { Table } 2 \\
\text { Modularity group displayed by intention to vote and party }\end{array}$} \\
\hline \multirow[t]{2}{*}{ Group } & \multirow{2}{*}{$\begin{array}{l}\text { Number } \\
\text { in group }\end{array}$} & \multicolumn{3}{|c|}{ Intention to vote } & \multicolumn{4}{|c|}{ Party } \\
\hline & & Remain & Leave & Undeclared & Labour & Conservative & SNP & Other \\
\hline Group 1 & $120(28.6 \%)$ & $109(90.8 \%)$ & $11(9.1 \%)$ & $0(0 \%)$ & $20(16.7 \%)$ & $96(80 \%)$ & $2(1.67 \%)$ & $2(1.67 \%)$ \\
\hline Group 2 & $153(36.42 \%)$ & $85(55.6 \%)$ & $66(43.1 \%)$ & $2(1.3 \%)$ & $36(23.53 \%)$ & $81(52.9 \%)$ & $27(17.6 \%)$ & $9(5.89 \%)$ \\
\hline Group 3 & $147(35 \%)$ & $133(90.5 \%)$ & $13(8.84 \%)$ & $1(0.68 \%)$ & $116(78.9 \%)$ & $22(14.9 \%)$ & $5(3.4 \%)$ & $4(2.72 \%)$ \\
\hline Total & 420 & 327 & 90 & 3 & 172 & 199 & 34 & 15 \\
\hline
\end{tabular}

MPs intention to vote data, BBC 2016.

\subsection{Communication between MPs during the referendum campaign}

From the data collected, we located 1,909 separate incidences of communication between MPs during the referendum campaign. Using these actions for the basis of analysis, we were able to assess overall networks during the campaign and the groups in which MPs reside. To test this, we created a series of network graphs. Graph 2 displays the network actions by MPs during the campaign. For this, we used the OpenOrd layout that is used for distinguishing clusters within a given network (Martin et al., 2011). We coloured each node by party membership to test if partisanship remained a prominent factor in the make-up of online groups. Analysis of the graph shows three major groups within the network, and furthermore, that while there is some correlation between party and the groups, there are significant other factors in determining the make-up of the network. This is important, as it has the potential to demonstrate that while the normal relationship between MPs is defined by party membership as shown by the follower relationship graphs, when focusing on particular issues such as the EU referendum, party has less significance in defining areas within the structure of the network.

To further understand the changes within this network, and to detect the factors that determine the membership of the groups within the graph, we undertook analysis through the use of modularity classes. We found eight different groups based upon modularity. Five of the groups only contained nine MPs between them and therefore are omitted from further analysis due to lack of statistical power. The three main groups can be seen in Graph 3, which is a network graph of all actions taken between MPs during the campaign, coloured by their respective classes. This shows that each group is closely interlinked, and while there is communication between each group, this is not as significant as those within the groups themselves. Table 2 outlines the characteristics of each group in terms of group figures, intention to vote in the referendum, and party membership. The makeup of each group shows particular characteristics. Group 1 is characterised by a high index of Conservatives who wish to remain in the EU. Similarity, group 3 is also pro-remain but is largely made up of Labour MPs. Group 2 is significantly different. This group has a greater mix of party memberships compared to groups 1 and 3, but much more pro-Leave than the two other groups.

Through further analysis, it was found overall groups 1 and 3 shared a relative commonality of support for the Remain campaign, and this can be seen in comparison to group 2 in Graph 3. However, the groupings show the deep party political divisions across the Remain campaign, suggesting a less united front than perhaps the Remain campaign would have wanted to create. Although MPs in both group 1 and 3 supported the same cause, party politics remained a centralising factor. Suggesting although MPs may support a shared cause, it was not greater than their desire to focus on party communication on Twitter.

Group 2 showed a significant difference in overall composition, its membership was less defined by party, and more inclusive of a wider range of partisan support. Furthermore, group 2 MPs were more likely for to vote to leave the EU, than groups 1 and 3 . Notably, it was also found this group 
Graph 3. MPs network of communication based from actions during the referendum campaign coloured by modularity. Created using OpenOrd Layout. Each MP (displayed as nodes) has been identified by the three modularity classes. The size of the Nodes and Labels are dependent on their importance within the network (Eigenvector).

contained a number of SNP and other third party representatives in the dataset. This inclusion of thirdparty MPs, despite their support for remain, is interesting. It would go someway to suggest that MPs from smaller remain supporting parties actively tried to cross the boundaries of the network set by Labour and Conservatives in an attempt to reach out or potentially debate with leave supporting MPs. This largely explains their high degree of communication and inclusion within this group. Similarly, there are a number of Labour and Conservative MPs who overall supported remaining in the EU, but were using 
L. McLoughlin et al. / A tale of three tribes: UK MPs, Twitter and the EU Referendum campaign

Table 3

MPs ranked by Eigenvector-Centrality

\begin{tabular}{|c|c|c|c|c|}
\hline MP & Eigenvector-Centrality & Party & EU ref voting intention & Modularity group \\
\hline Boris Johnson & 1 & Conservative party & Leave & 2 \\
\hline Harriet Harman & 0.932 & Labour party & Remain & 3 \\
\hline Gisela Stuart & 0.882 & Labour party & Leave & 2 \\
\hline Priti Patel & 0.879 & Conservative party & Leave & 2 \\
\hline Jeremy Corbyn & 0.787 & Labour party & Remain & 3 \\
\hline Penny Mordaunt & 0.764 & Conservative party & Leave & 2 \\
\hline Angela Eagle & 0.755 & Labour party & Remain & 3 \\
\hline Sadiq Khan & 0.686 & Labour party & Remain & 3 \\
\hline John McDonnell & 0.662 & Labour party & Remain & 3 \\
\hline Andrea Leadsom & 0.622 & Conservative party & Leave & 2 \\
\hline John Mann & 0.575 & Labour party & Leave & 2 \\
\hline David Cameron & 0.533 & Conservative party & Remain & 1 \\
\hline Kate Hoey & 0.525 & Labour party & Leave & 2 \\
\hline Chuka Umunna & 0.469 & Labour party & Remain & 3 \\
\hline Ed Miliband & 0.411 & Labour party & Remain & 3 \\
\hline Ed Vaizey & 0.405 & Conservative party & Remain & 1 \\
\hline Caroline Lucas & 0.381 & Green party & Remain & 3 \\
\hline Tom Watson & 0.379 & Labour party & Remain & 3 \\
\hline Nadhim Zahawi & 0.372 & Conservative party & Leave & 2 \\
\hline Amber Rudd & 0.35 & Conservative party & Remain & 1 \\
\hline Nadine Dorries & 0.349 & Conservative party & Leave & 2 \\
\hline Steve Baker & 0.348 & Conservative party & Leave & 2 \\
\hline Mary Creagh & 0.335 & Labour party & Remain & 3 \\
\hline Hilary Benn & 0.315 & Labour party & Remain & 3 \\
\hline Sarah Wollaston & 0.302 & Conservative party & Remain & 1 \\
\hline
\end{tabular}

Twitter to discuss the referendum with their campaign opponents. Therefore, this group signifies MPs who wish to leave the EU and also those more willing to cross party and ideological barriers to challenge the online campaign messages of the Leave side. This group, therefore, has a somewhat divergent split within it with a closely connected core group of leave supporters and a more marginal remain subset towards the outside of the group.

\subsection{Measuring prominence/importance amongst MPs}

While measuring the importance of a particular node within a network is important, there are a range of statistics that can be used. Here, we deployed the statistical algorithm Eigenvector-Centrality (Tarjan, 1972). ${ }^{5}$ This produces a figure that can be used as measure of relative importance of every node across the overall structure of the network, rather than the groups within which they reside. This measure is useful for understanding the MPs who had the most prominence in the campaign amongst all MPs. In Graphs 3 and 4 each node is sized based upon Eigenvector-Centrality, with the bigger nodes having a relative importance across the network. This suggests when MPs are discussing particular issues there are individuals who hold significant prominence across the network in contrast to others.

Table 3 lists all MPs with an Eigenvector-Centrality range of 1 to 0.3 ; with 1 being the most prominent/important MP within the network. These are listed alongside party, modularity class, and intention to vote. The table shows that MPs with significant pre-existing profile have a higher importance within the network. The list includes the leaders of the two main parties (Conservative and Labour), and senior

${ }^{5}$ For further information on the ranking algorithms used, please see Hanneman and Riddle, 2005. 
14 L. McLoughlin et al. / A tale of three tribes: UK MPs, Twitter and the EU Referendum campaign

government ministers. Furthermore, the characteristics of modularity groups who these MPs belong to, align closely, suggesting these are not only the most important, in terms of connections within the network, but also in terms of defining the groups in which they belong. It is no surprise perhaps that Boris Johnson was the most prominent MP in the data considering his high profile role in the Leave campaign. What is perhaps more surprising is the position of the Conservative Party leaders. PM David Cameron was not a particular prominent figure in the data, below some backbench MPs such as John Mann, and below opposition leader Jeremy Corbyn. This is interesting in that Corbyn was heavily criticised for his apparently lacklustre campaigning during the referendum (Wilson, 2016; Dugdale 2017) and yet, on Twitter at least, he was more central than David Cameron. However, in other ways this is not so surprising. Corbyn's prominence and successful leadership campaign is often attributed to a savvy use of social media (Prince, 2016) and so centrality in online networks might be expected and, therefore, replicated within the network of MPs. Our data implies that this is due to them having a greater retweet ratio to other MPs. However, without further analysis, which is beyond the scope of this paper, these data alone cannot be used to understand why these particular MPs are so prominent within the network. There are further, indications from the way MPs are grouped to suggest that politicians within smaller networks, such as the Leave side, are more supportive of each-other irrespective of party when compared to the larger Remain side. This would explain the unexpected importance of some members and, moreover, suggests that social media is contributing to the erosion of strict hierarchies of importance based on status. Several relative unknowns (at the time) were prominent in the data in a way that they were not in the press coverage of Brexit (Harmer et al., 2016) e.g. Steve Baker (Conservative, Leave, MP).

\section{Discussion and conclusions}

The social media data deployed here has important methodological implications for research on politicians' interpersonal relationships. It provides a window into their overarching communication networks without the requirement of accessing private emails, letters, or spoken conversations that previously were difficult to gain. In this article, we have used this window to create a greater understanding of how MPs have communicated over the duration of the European referendum campaign to find which MPs are talking to each other, and the contents of this communication. Although here we focus on a specific, (and, as demonstrated, rather unusual campaign), this has implications more broadly for understanding political elite communication networks.

The referendum campaign was a rare event in UK politics. Political representatives from a range of political parties campaigned together, providing potentially fertile ground for, inter-party linkages. This was a significant opportunity therefore to test whether partisanship remains even on such a divisive topic. One the whole, it does seem that partisanship held up, particularly when considering groups 1 and 2 in our modularity analysis. Essentially, the Remain campaign split into two 'camps' largely divided by party (and more specifically, the two largest parties). These groupings suggest two things: Firstly, a majority of Remain supporters, regardless of the shared and important cause in question here, still sought to campaign along party lines; Secondly, party politics is being replicated and possibly even reinforced online rather than being eroded as early scholars in this area predicted (Ward \& Gibson, 1998; Margolis \& Resnick, 2001). This chimes with wider findings about online polarisation primarily existing amongst the most political active and engaged groups within society rather than regular voters (Prior, 2013: Pacewicz, 2016).

However, partisanship was less influential between MPs within group 2. This group, can be summarised as comprising the vast bulk of the Leave supporting MPs with a sprinkling of Remain MPs who 
wished to interact or debate the subject. Therefore, the Leavers within the group are the exception to the theory regarding UK MPs and partisanship. It seems that for these MPs the cause of leaving the EU was more important to them than party attachment, and they were happy to welcome those who were not in their party into the fold. This would partly explain why some MPs such as Gisela Stuart, Steve Baker, and Kate Hoey, hardly prominent figures normally, had a significantly increased importance within MPs' Twitter networks. It is possible that the rarity of Labour Leavers increased their currency as figureheads for this position in the debate, nevertheless, it underlines that they were as firmly part of the group being tagged and re-tweeted often by other Leavers, regardless of party affiliation. Overall then, MPs who supported Leave banded together much more effectively than their respective Remain supporters who seemingly put party ahead of the Remain cause.

The findings here have important implications for campaigning more broadly. The Leave campaign seemingly coalesced around their cause, regardless of party loyalties. This cannot be said to the same extent for the Remain camp. Lessons could be learnt here for Remain supporters, and particularly if the prospect of a 'People's Vote' (i.e. a second referendum on the terms of withdrawing versus the option of remaining) comes to fruition. Rather than replicating the fractious Remain campaign, which some have suggested spilled over into their campaign communications (Behr, 2016), if they were to stand any chance of winning this second vote, the evidence here suggests that they should at least project a more unified cross-party front.

In terms of our second area of concern (intra-party networks), when assessing whether social media may be eroding traditional party hierarchies, there is some evidence here to suggest it does in certain circumstances and on an issue basis lending support to Del Valle and Borge's (2017) idea of the emergence of online brokers and new influences in parliamentary networks. Several less prominent MPs were central within their networks. Harriet Harman, although a clearly prominent figure in the Labour Party, was a backbencher at the time and yet was second only the Boris Johnson in terms of eigenvector centrality here. Several backbench MPs attained a higher centrality than Prime Minister David Cameron, who could well be considered the 'face' of the Remain campaign and yet was not particularly central considering his status. This would suggest that within issue-based, social networks, party leaders play a less significant role than their offline position would suggest. It seems not only does social media allow for a greater level of independence away from core party lines, but that within MPs networks, traditional hierarchies have less influence in online debates.

In short, the unusual EU campaign offered an opportunity to create a greater understanding of the nature of elite communication networks. It showed that the expectations of strong levels of divide on a single issue across political parties can be seen on social media communication, and while the majority of MPs networks remained based on expected party lines, small groups of cross party MPs, who share a common cause, may can be found banding together in supportive alliances. Arguably, social media has therefore widened the potential for inter-party connections that don't readily exist offline. Furthermore, the study indicates even stronger potential for disruptive intra-party impacts, where social media can allow politicians to be prominent online outside of traditional formal party structures. However, partly because of the atypical nature of the case study here, means that to deepen our understanding of parliamentary communicative networks further research is required in at least three respects: Firstly, whilst our results provided a snapshot, the monitoring of the parliamentary communicative networks over time would help trace shifts in connections and the drivers of change (especially across parliamentary sessions). Three years on from the referendum, it would be useful to see whether the networks outlined here have become further entrenched and whether they have started spill-over into other areas. For instance, how far the intra-party networks around 2019 Conservative Party leadership contest reflect some of the 
internal divides we detected in 2016. Secondly, study is also required around the everyday, and sometimes less polarised, issues of parliamentary business, where there might be scope for more inter-party cooperation and communication. The more routine and less partisan driven issues might be expected to foster more inter-party communication networks. Finally, our research has concentrated on one platform (Twitter), the most public of the social media communication networks. It would be interesting to compare these networks with other social media platforms, for example, the rise of the relatively closed world of WhatsApp discussion groups within the parliamentary parties (Elgot, 2017). These private networks have become more central to intra-party discussions, in particular, but raise considerable methodological and ethical challenges for researchers in how to access and study them.

\section{References}

Barbera, P. (2015). How Social Media Reduces Mass Political Polarization: Evidence from Germany, Spain, and the U.S., Paper presented at the 2015 Annual Meeting of the American Political Science Association, San Francisco, September $3^{\text {rd }}-6^{\text {th }}$.

Bastian, M., Heymann, S., \& Jacomy, M. (2009). Gephi: an open source software for exploring and manipulating networks. International AAAI Conference on Weblogs and Social Media. Available at: https://www.aaai.org/ocs/index.php/ICWSM/ 09/paper/view/154/1009.

BBC. (2016). EU vote: Where the cabinet and other MPs stand. $22^{\text {nd }}$ June. http://www.bbc.co.uk/news/uk-politics-eu-referend um-35616946.

Behr, R. (2016). How Remain Failed: The Inside Story of a Doomed Campaign. The Guardian $5^{\text {th }}$ July, 2016. Accessed $27^{\text {th }}$ Feb 2019.

Beninger, K., Fry, A., Jago, N., Lepps, H., Nass, L., \& Silvester, H. (2014). Research Using Social Media; User's Views. London: NatCen. http://www.natcen.ac.uk/media/282288/p0639-research-using-social-media-report-final-190214.pdf.

Binns, K. (2018). Look out loan sharks - I'm still hunting you. The Sunday Times, June 3. Available at: https://www.thetimes. co.uk/article/stella-creasy-look-out-loan-sharks-i-am-still-hunting-you-2hgmg6gfr. [Accessed 29 March 2019].

Cantor, D.M., \& Herrnson, P.S. (1997). Party campaign activity and party unity in the US House of Representatives. Legislative Studies Quarterly, 22, 393-415.

Cowley, P., \& Stuart, M. (1997). Sodomy, slaughter, Sunday shopping and seatbelts: free votes in the house of commons, 1979 to 1996. Party Politics, 3(1), 119-130.

Cowley, P. (1998). Unbridled passions? Free votes, issues of conscience and the accountability of British members of parliament. The Journal of Legislative Studies, 4(2), 70-88.

Deacon, D.N., \& Wring, D.J. (2011). Reporting the 2010 General Election: Old Media, New Media - Old Politics, New Politics. In Wring, D., \& Mortimore, R. (eds), Political Communication in Britain: The Leader Debates, the Campaign and the Media in the 2010 General Election. Basingstoke, Palgrave Macmillan, pp. 281-303,

Del Valle, M., \& Borge, R. (2017). Leaders or broker? Potential influencers in online parliamentary networks. Policy \& Internet, 10(1), 61-85.

Dubois, E., \& Blank, G. (2018). The echo chamber is overstated: the moderating effect of political interest and diverse media. Information, Communication \& Society, 21(5), 729-745.

Dugdale, K. (2017). From Corbyn to Cameron, we all share the blame for the Brexit shambles. Daily Record, September 26. Available at: https://www.dailyrecord.co.uk/news/politics/corbyn-cameron-share-blame-brexit-11234943. [Accessed 2 April 2019].

Effing, R., van Hillegersberg, J., \& Huibers, T. (2011). Social media and political participation: Are Facebook, Twitter and YouTube democratising our political systems? In Tambouris, E., Macintosh, A., \& De Bruijn, H. (eds), Lecture Notes in Computer Science, Berlin/Heidelberg, Springer, pp. 25-35.

Elgot, J. (2017). WhatsApp: The go-to messaging tool for Parliamentary plotting' Guardian June 12. Available at: https://the guardian.com/politics/2017/Jun/12/WhatsApp-The-go-to-messaging-tool-for-Parliamentary-plotting. [Accessed 21 June 2019].

Enli, G.S., \& Skogerbø, E. (2013). Personalized campaigns in party-centred politics. Information, Communication \& Society, 16(5), 757-774.

Fletcher, R., \& Nielsen, R.K. (2018). Are people incidentally exposed to news on social media? A comparative analysis. New Media \& Society, 20(7), 2450-2468.

Francoli, M., \& Ward, S.J. (2008). 20th century soapboxes? MPs and their blogs. Information Polity, 13(1-2), 21-39.

Gallucci, N. (2018). Beto and AOC have Mastered Instagram Stories. Mashable. November $12^{\text {th }} 2018$. [Accessed $4^{\text {th }}$ February 2019]. 
Gibson, R.K. (2013). Party change, social media and the rise of 'Citizen-Initiated' campaigning. Party Politics, 21(2), 183-19. Gibson, R.K., \& Ward, S.J. (2009). Parties in the digital age: a review article. Representation, 45(1), 87-100.

Gibson, R.K., \& Ward, S.J. (2012). Political Organizations and Campaigning Online. In Semetko, H., \& Scammell, M. (eds), The Handbook of Political Communication. London: Sage.

Gibson, W.S. (2015). Jeremy Corbyn - Accidental Hero. London: Eyewear Publishing.

Gil de Zúñiga, H., \& Valenzuela, S. (2011). The mediating path to a stronger citizenship: online and offline networks, weak ties, and civic engagement. Communication Research, 38(3), 397-421.

Granovetter, M. (1983). The strength of weak ties: a network theory revisited. Sociological Theory, 1, $201-233$.

Grant, W.J., Moon, B., \& Grant, J.B. (2010). Digital dialogue? Australian politicians' use of the social network tool Twitter. Australian Journal of Political Science, 45(4), 579-604.

Hanneman, R.A., \& Riddle, M. (2005). Introduction to Social Network Methods. Riverside, CA: University of California. Available online at: http://faculty.ucr.edu/ hanneman/nettext/index.html.

Harmer, E. (2016). 'Brexit 'mansplained': news coverage of the EU Referendum'. In Jackson, D., Thorsen, E., \& Wring, D. (eds), EU Referendum Analysis 2016: Media, Voters and the Campaign. Bournemouth: Centre for the Study of Journalism, Culture and Community.

Hsu, H.L., \& Park, H.W. (2012). Mapping online social networks of korean politicians. Government Information Quarterly, 29, 169-81.

Jackson, N., \& Lilleker, D. (2011). Microblogging, constituency service and impression management: UK MPs and the use of Twitter. Journal of Legislative Studies, 17(8), 86-105.

Karvonen, L. (2010). The personalisation of politics: a study of parliamentary democracies. ECPR Press, London.

Kruikemeier, S. (2014). How political candidates use Twitter and the impact on votes. Computers in Human Behaviour, 34, 131-139.

Lassen, D.S., \& Brown, A.R. (2011). Twitter: the electoral connection? Social Science Computer Review, 29, 419-436.

Leston-Bandeira, C. (2007). The impact of the internet on parliaments: a legislative studies framework. Parliamentary Affairs, $60(4), 655-674$.

Lo Dico, J. (2018). Labour MP David Lammy Windrush, Grenfell and using Twitter to address race bias. London Evening Standard, May $23^{\text {rd }}$. Available at: https://www.standard.co.uk/lifestyle/esmagazine/david-lammy-interview-labour-mp-eveningstandard-interview-windrush-grenfell-a3844871.html. [Accessed 4 April, 2019]

Lusoli, W., \& Ward, S.J. (2005). From weird to wired: MPs, the internet and representative politics in the UK. Journal of Legislative Studies, 11(1), 57-81.

Margetts, H., John, P., Hale, S., \& Yasseri, T. (2015). Political Turbulance: How social media shapes collective action. Princeton University Press, Princeton.

Margolis, M., \& Moreno-Riaño, G. (2013). The prospect of internet democracy. Basingstoke: Ashgate Publishing.

Margolis, M., \& Resnick, D. (2001). Politics as Usual: The CyberspaceRevolution. New York, Sage.

Martin, S., Brown, W.M., Klavans, R., \& Boyack, K. (2011). Open Ord: An Open-Source Toolbox for Large Graph Layout. Paper Presented to the SPIE 7868 Conference on Visualisation and Data analysis, January 24, San Francisco Airport, CA, U.S.

Markham, A., \& Buchanan, E. (2012). Ethical Decision-making and Internet Research: Version 2.0 - Recommendations from the Association of Internet Researchers Working Committee. Chicago, IL: AOIR. http://aoir.org/reports/ethics2.pdf.

McLoughlin, L. (2016, June 20). Measuring the Growth of Twitter Uptake Among the Current Cohort of MPs. [Weblog Post]. Available from: http://leelum.com/blog/social-media/measuring-the-growth-of-twitter-uptake-among-the-currentcohort-of-mps/ (Accessed September $\left.6^{\text {th }}, 2016\right)$.

McPherson, M., Smith-Lovin, L., \& Cook, J.M. (2001). Birds of a feather: homophily in social networks. Annual Review of Sociology, 27(1), 415-444.

Negrine, R. (1999). Parliament and the Media. A Study of Britain, Germany and France. London, Royal Institute of International Affairs/Cassell.

Negrine, R., \& Lilleker D. (2003). The rise of a proactive local media strategy in british political communication: clear continuities and evolutionary change 1966-2001. Journalism Studies, 4(2), 199-211.

NESTA. (2015). The Twitter network for UK MPs. Available at: http://www.nesta.org.uk/blog/twitter-network-uk-mps. [Accessed 20 March 2017].

Norris, P., Curtice, J., Sanders, D., Scammell, M., \& Semetko, H.A. (1999). On message: Communicating the campaign. Sage: London.

Pacewicz, J. (2016). Partisans and Partners: The Politics of Post Keynesian Society. Chicago, University of Chicago Press.

Prince, R. (2016). Comrade Corbyn: A Very Unlikely Coup: How Jeremy Corbyn Stormed to the Labour Leadership. London, Biteback publications.

Prior, M. (2007). Post Broadcast Democracy: How Media Choice Increases Inequality in Political Involvement and Polarizes Elections. Cambridge, Cambridge University Press.

Prior, M. (2013). Media and political polarization. Annual Review of Political Science, 16, 101-127. 
18 L. McLoughlin et al. / A tale of three tribes: UK MPs, Twitter and the EU Referendum campaign

Rauchfleisch, A., \& Metag, J. (2016). The special case of switzerland: swiss politicians on Twitter. New Media \& Society, $18(10), 2413-2431$

Sæbø Ø. (2011). Understanding Twitter ${ }^{\mathrm{TM}}$ Use among Parliament Representatives: A Genre Analysis. In Tambouris E., Macintosh A., \& de Bruijn, H. (eds), Electronic Participation. ePart 2011. Lecture Notes in Computer Science, vol 6847. Berlin, Heidelberg, Springer.

Salmons, J., \& Woodfield, K. (2013). Social Media, Social Science \& Research Ethics. London, NatCen. http://the-sra.org.uk/ wp-content/uploads/salmons_woodfield.pdf.

Sandoval-Almazan, R., \& Valle-Cruz, D. (2018). Towards and understanding of Twitter networks: the case of the state of mexico. First Monday, 23(4). NP.

Simon, A.F. (2002). The winning message: Candidate behavior, campaign discourse, and democracy. Cambridge, Cambridge University Press.

Smith, M., Milic-Frayling, N., Shneiderman, B., Mendes Rodrigues, E., Leskovec, J., \& Dunne, C. (2010). NodeXL: a free and open network overview, discovery and exploration add-in for Excel 2007/2010, http://nodexl.codeplex.com/ from the Social Media Research Foundation, http://www.smrfoundation.org.

Southern, R. (2015). Is web 2.0 providing a voice for outsiders? A comparison of personal web site and social media use by candidates at the 2010 UK general election. Journal of Information Technology \& Politics, 12(1), 1-17.

Southern, R., \& Lee, B. (2019). Politics as usual? Assessing the extent and content of candidate-level online campaigning at the 2015 UK general election. Journal of Elections, Public Opinion and Parties, 29(2), 179-198.

Sunstein, C.R. (2006), Republic.com, $2^{\text {nd }}$ Edition, Princeton: Princeton University Press.

Takemura, G., Tanaka, A., \& Tajima, K. (2015). Classification of Twitter follow links based on Follower's intention. Proceedings of the 30th Annual ACM Symposium on Applied Computing, 1174-1180.

Tarjan, R. (1972). Depth-first search and linear graph algorithms. SIAM Journal on Computing, 1(2), 146-160.

Thamm, M., \& Bleier, A. (2013). When Politicians Tweet: A Study on the Members of the German Federal Diet. In ACM Web of Science. Paris. Available at: http://arxiv.org/ftp/arxiv/papers/1305/1305.1734.pdf.

Tresch, A. (2009). Politicians in the media: determinants of legislators' presence and prominence in swiss newspapers. International Journal of Press/Politics, 14(1), 67-90.

Twitter. (2016). Developer Agreement \& Policy, Twitter Developer Agreement Effective: June 10, 2016. [Accessed July $23^{\text {rd }}$ 2016] https://dev.twitter.com/overview/terms/agreement-and-policy.

Valeriani, A., \& Vaccari, C. (2016). Accidental exposure to politics on social media as online participation equalizer in Germany, Italy, and the United Kingdom. New Media \& Society, 18(9), 1857-1874.

van Aelst, P., Sheafer, T., \& Stanyer, J. (2012). The personalization of mediated political communication: a review of concepts, operationalizations and key findings. Journalism, 13(2), 203-220.

van Zoonen, L. (2005). Entertaining the citizen: when politics and popular culture converge. Lanham, MD: Rowman and Littlefield

Ward, S.J., \& Gibson, R.K. (1998). The First Internet Election? UK political parties and campaigning in cyberspace. In Crewe, I., et al. (eds), Political Communications: Why Labour Won the General Election of 1997, London: Frank Cass, pp. 93-107.

Wilson, P. (2016). Corbyn sabotaged Labour's remain campaign - He must resign. The Guardian, June 26. Available at: https://www.theguardian.com/commentisfree/2016/jun/26/corbyn-must-resign-inadequate-leader-betrayal. [Accessed 2 April 2019]. 